\title{
UNDERSTANDING VACCINE HESITANCY AS EXTENDED ATTITUDES
}

\author{
SIMONA VULPE \\ Interdisciplinary School of Doctoral Studies, University of Bucharest, Romania
}

(c) 2020 Simona Vulpe

This is an open access article distributed under the Creative Commons Attribution-NonCommercial-NoDerivs license (http://creativecommons.org/licenses/by-nc-nd/3.0/)

DOI: 10.1515/eras-2020-0005

\begin{abstract}
Vaccine hesitancy is not a singular view but encompasses a set of positions located between complete acceptance of vaccination and complete rejection of vaccination. In this paper, I argue that vaccine-hesitant attitudes emerge at the intersection of individual and structural processes, and thus can be better conceptualized as "extended attitudes". Drawing on the theoretical understanding of risk and science scepticism in post-modern societies, I consider hesitant attitudes towards vaccination as addressing risks that are induced in our everyday lives by science developments. I conducted K-Means Cluster Analysis on Eurobarometer data from 2019 regarding Europeans' attitudes towards vaccination. Four clusters of vaccine-hesitant attitudes were identified. "Price hesitation" and "Effort hesitation" result from restricted access to vaccination because of structural constraints, such as low economic capital and health care system' deficits. "Unexercised pro-vaccination" is an attitude manifested by people who grant authority to science to manage health-related risks, even though they did not vaccinate in the last five years. "Consistent anti-vaccination" pertains to highly reflexive individuals who dismiss experts' authority because of scientifically derived risks. My analysis enhances the theoretical understanding and the empirical assessment of vaccine-hesitant attitudes in the European Union and can inform public health policies in this area.
\end{abstract}

\section{Keywords}

vaccine hesitancy, cluster analysis, European Union, extended attitude, risks, health care

\section{Introduction}

Vaccine hesitancy can be regarded either as a response to scientifically induced risks or as a risk in itself. Despite the fact that global vaccination coverage has gradually increased over time, there still were 13.5 million unvaccinated children in 2018 (Vanderslott, Dadonaite \& Roser, 2019). The insufficient vaccination coverage is partly attributed to vaccine hesitancy. In Eastern Europe, $20 \%$ of the population does not think that vaccines are important for children and $17 \%$ of the population in Western Europe declares the same. In North America, the percentage is lower, $13 \%$ of the population saying that vaccines are not important for children. Most people in South Asia and South America support vaccination of children, only 2\% and $3 \%$ respectively declaring that vaccines are not important for children (Ibidem).

Why do people reject a medical artifact that was once considered a life-saving medicine? The explanation resides in various risks that take over society nowadays, most of them having emerged from science and technology developments and acting as co-constitutive properties of hesitant attitudes. Starting from the conceptualization of extended cognition, I argue that vaccine hesitancy attitudes are also extended.

Extended cognition allows for "hybrid cognitive systems" (Sutton, Harris, Keil \& Barnier, 2010, 525), which consist in individual and external properties functioning together. 
Extended cognition is based on the connection between agent and external elements, such as technological and social resources (Ibidem, 521). Cognitive action is extended by "manipulation and exploitation of environmental structures" (Kruger, 2011, 140). Social and technological resources work complementarily with individual characteristics, despite being disparate properties. Cognition is also socially extended. An individual's mental processes are shaped by and constantly connected to the mental states of other agents (Clark \& Chalmers, 1998, 18). Therefore, external resources are co-constitutive for cognitive actions (Sutton et al., 2010, 531).

Similarly to individual cognitive actions being scaffolded by external sources (Wikforss, 2014), vaccine-hesitant attitudes are scaffolded by socially organized health care systems and their affordances (MacArthur, 2017). Attitudes towards vaccination are influenced by the social context of science developments and their associated risks. Nowadays, "science is more complex and embedded in society than ever before" (Simis, Madden, Cacciatore \& Yeo, 2016, 401). The public understanding of science and expertise shifted from granting authority to the scientific community to manifesting scepticism towards experts.

From a historical perspective, Beck (1992) identifies the primary scientization as the first wave, when the public trusted science based on the distinction between non-professionals and experts. Under these circumstances, science represented the authority of the industrial society, breaking away from traditions and common knowledge. According to Giddens (1999), science managed to replace tradition due to its authoritarian style. But as science became increasingly important in society, the scepticism it entailed extended towards "its own foundations and practical results" (pp. 155-156). Furthermore, according to Beck (1992) in the second wave people began to experience risks related to modernization, which gave rise to criticism targeting science. Some of this criticism morphed into opposition against scientific and technological artefacts, the anti-vaccination movement being an example in this regard. Such movements make use of cultural resources in order to assign definitions and significations to scientific artefacts and thus to manufacture doubt. "Social definitions and relationships" are the key issues in constructing science-derived risks, as Beck noted (p. 160).

\section{The post-modern liberation of risks}

Healthism is a symptom of the risk society in which people act as reflexive agents who make decisions regarding their health (Giddens, 1999, 9). Healthism reflects the junction between reflexivity and managing health-related risks individually. This state of affairs emerged under the circumstances of demonopolisation of scientific knowledge (Beck, 1992, 156). The harmful effects of various products, such as medication, are acknowledged by experts, who decide on acceptable levels of risk. Their expertise is contested by the public on the basis of scepticism and insufficient evidence (Giddens, 1999, 8). Expertise is caught in a death spiral since trust, which mediates the relationship between experts and public, is eroded (Nichols, 2017). The lack of trust manifested by the public towards experts gives rise to "warring factions" (Ibidem, 216).

Junk science is held responsible for the spread of science scepticism (Prior, 2003; Brunk, 2006) because it feeds the sceptical faction of the public. For example, the antivaccination movement "cherry picks" scientific articles that validate their opinions (Nature Immunology Editorial, 2008). Anti-vaxxers defend their position by advancing critics of undemocratic and elitist approaches to scientific knowledge (Nichols, 2017). The authoritarian character of science is contested by these post-modern actors for whom reflexivity is a valuable resource.

Scientific claims may be the foundation of lay people's decisions, along with other cultural references, such as religious beliefs or personal experiences. The knowledge deficit 
model, which asserts that the public lacks correct scientific information, neglects the cultural resources outside the scientific spectrum that people take into account when managing risks in their everyday lives (Brown, 2009). Public policies based on the knowledge deficit model are "negating and dismissing values and viewpoints that have legitimacy in their own right" (Brunk, 2006, 180). The deficit model protects the authority of science and opposes the demonopolisation of scientific knowledge. However, in contrast to the knowledge deficit model assertions, several sociological studies have shown that the public is able to understand science, as well as the uncertainties and risks related to scientific findings (Bucchi \& Neresini, 2008; Jasanoff, 2012; Pouliot \& Godbout, 2014).

The knowledge deficit does not only pertain to the public, but experts also are confronted with various forms of deficits (Brunk, 2006). The formal training and education process of scientists might cause a fracture between experts and the public because of the former's lack of public communication abilities. Moreover, some experts are not aware of how the public reaches to and engages with scientific information and how this information is further condensed into public opinion (Simis et al., 2016, p. 403).

\section{The heterogeneity of vaccination views}

Attitudes towards vaccines and the cultural resources that support vaccination decisions vary across the population. The World Health Organization (WHO) defined vaccine hesitancy as occurring "when vaccine acceptance in a specific setting is lower than would be expected, given the availability of vaccine services" (World Health Organization, 2014, 8). However, MacDonald (2015) advances a broader definition, considering vaccine hesitancy as a "set on a continuum between those that accept all vaccines with no doubts, to complete refusal with no doubts, with vaccine hesitant individuals the heterogeneous group between these two extremes" (pp. 1-2). Beyond factors such as confidence, hesitancy or complacency, there are access barriers that impede people from receiving vaccinations. These access barriers mostly consist of economic disadvantages (Bedford et al., 2018; Peretti-Watel et al., 2019).

On the issue of vaccination, "parents are not homogenous" (Keane et al., 2005, 2493). Their vaccination views are dynamic in time and vary according to contextual specificities, such as the vaccine that is going to be administrated and the communication and media environment (MacDonald, 2015). Keane et al. (2005) studied US parents' confidence in vaccination and identified four groups of parents, based on a multivariate analysis: Vaccine Believer - confident of vaccines' beneficial effects, Cautious parents - "high emotional investment in their child", Relaxed parents - less involved parenting style and sceptical about vaccination, and Unconvinced parents - lack of trust in vaccines (p. 2486). Cautious parents are remarkable in their opposition to vaccines. Their rejection motive is the difficulty to watch their child suffering while being vaccinated, despite the fact that they recognize vaccines as important (p. 2492). Other classifications of US parents based on their vaccination decisions led to the identification of the following groupings: parents having a "naive understanding of vaccination mechanisms" and parents having an understanding "focused on immunity"; parents who make vaccination decisions based on health considerations and parents who make vaccination decisions based on risk considerations (Downs, Bruine de Bruin, \& Fischhoff, 2008, 1604).

Constantine and Jerman (2007) grouped the Californian parents who reject the HPV vaccination in five clusters, based on their rejection reasons. The clusters that resulted were: parents concerned about vaccine's effect on sexual behaviour, parents concerned about the specific effects of the HPV vaccine on health, parents morally concerned about sexual behaviour, parents concerned about vaccines generally, and parents who denied the need of the HPV vaccination. Perez et al. (2015) classified Canadian parents based on their HPV 
vaccination decisions for their sons. According to their classification, parents were unaware (of boys' eligibility for the HPV vaccine), unengaged (in the vaccination debate), undecided, decided not to vaccinate, decided to vaccinate, and vaccinated (p. 1316).

The analysis that I conduct captures multiple vaccine-hesitant attitudes that transcend the anti-vaxx vs. pro-vaxx dualism. I document hesitancy towards vaccination as a set of extended attitudes, at the intersection of individual and structural mechanisms. This analysis is based on a multi-dimensional assessment of Europeans' vaccination behaviour, using representative data for the European Union. This typology is not a parents-only grouping, but it considers respondents' vaccination attitudes irrespective of their parental status. Moreover, it uncovers the structural mechanisms responsible for low rates of vaccination. The analysis is relevant because it provides a comprehensive typology of vaccine-hesitant attitudes drawing on discursive resources anchored in health risks and fed by the demonopolisation of science.

\section{Data and methods}

\section{Data}

The data that I use were collected for the Eurobarometer 91.2 (European Commission, 2019): Europeans in 2019, The General Data Protection Regulation, Awareness of the Charter of Fundamental Rights of the European Union, and Europeans' attitudes towards vaccination and are representative for the 27 European Union Member States and the United Kingdom. Respondents were resident in the respective countries and aged 15 years and older. The total number of respondents was 27524. In terms of range of respondents at country level, the maximum was 1078 in Ireland and the minimum was 497 in Malta. After excluding cases coded "Inapplicable", the analysis was run on 15704 cases representing people who did not vaccinate in the last five years.

The sample used for data collection was a multi-stage, random probability one. For each of the countries included in the survey, stratification by individual unit and type of area was performed. Afterwards, a number of sampling points was systematically drawn according to the administrative regional units in order to ensure representativeness of the European Union countries in line with the EUROSTAT NUTS II (Gesis Leibnitz Institute for the Social Sciences, 2019).

\section{Variables}

The variables that I use to operationalize the concept of vaccine hesitancy measure respondents' reasons for not getting vaccinated in the last five years, respondents' attitude towards vaccines and their level of agreement with several statements regarding collective benefits of vaccination. I chose to include these variables in the analysis because the responses related to them point to various discursive patterns and discursive resources used by the respondents. Therefore, various groups can be identified based on respondents' propensity to advance certain reasons for not getting vaccinated, to accept statements that reinforce the vaccine-hesitant / anti-vaccine rhetoric and to agree or disagree with medical assertions about vaccines.

Respondents were asked about their reasons for not having received any vaccination in the last five years: Why have you not had any vaccination in the last five years? Respondents could choose multiple answers from a list of seven reasons: you are still covered by vaccines you received earlier; you do not see the need to be vaccinated; vaccines are only necessary for children; you have not been offered any vaccine by your general practitioner, a doctor, or a paediatrician; it is expensive; it is complicated and requires a lot of effort. The dataset contains dummy-coded variables corresponding to each of these reasons: the code 1 shows that the 
respondent mentioned the respective reason, whereas the code 0 shows that the respondent did not mention it. I excluded cases coded Inapplicable.

Another question was designed to capture the knowledge possessed by respondents in regard to vaccination: For each of the following statements, could you please tell me whether you think it is true or false? There were four items corresponding to this question, the variables being dichotomous ( 1 = True, 2 = False): vaccines overload and weaken the immune system; vaccines can cause the disease against which they protect; vaccines can often produce serious side-effects; vaccines are rigorously tested before being authorized for use. I recoded these variables as dummy-coded ones $(0=$ False, $1=$ True for the first three items and $0=$ True, $1=$ False for the last item).

Despite the attempt to capture respondents' vaccine knowledge, the Eurobarometer questions employed the perspective stemming from the medical, scientific area. According to this perspective, vaccine knowledge cannot be otherwise but pro-vaccine, whereas the vaccine hesitant or anti-vaccine position does not qualify as knowledge. This view on vaccination is congruent with the knowledge deficit model, which claims that non-scientists lack scientific information and scientific understanding, leading to the emergence of deviant bodies of knowledge. However, this perspective eludes the fact that people who oppose vaccination still possess vaccine knowledge. Even if this knowledge is invalid from the medical/scientific perspective, vaccine-hesitant and anti-vaccine people rely on information work and accounting practices to develop a body of knowledge that gets vehiculated, perpetuated and legitimized as valid knowledge within their community. Therefore, respondents' answers as True or False to this battery of questions rather capture their attitude towards vaccines, which can be hesitant or confident. These variables from Eurobarometer's database can be used as proxies in order to identify discursive resources that people make use of in order to manufacture doubt (Orekes \& Conway, 2010) with regard to vaccines.

The last question that I considered for my study is: To what extant do you agree or disagree with the following statements? Respondents rated several statements using a scale ranging from 1 (Totally agree) to 4 (Totally disagree): it is important for everybody to have routine vaccinations; vaccines are important to protect not only yourself but also others; vaccination of other people is important to protect those that cannot be vaccinated (e.g. new born children, immunodepressed or very sick people). This question captures respondents' agreement with collective benefits of vaccination. I recoded the variables corresponding to these statements into dichotomous ones, by collapsing categories and attributing the following codes: Totally agree and Agree formed one category coded $0=$ Agree, while Totally disagree and Disagree formed the category coded $1=$ Disagree .

\section{Analytical technique}

I conducted a K-Means Cluster Analysis using IBM SPSS Statistics 22. The analysis I conducted is exploratory, aiming to classify the respondents into several groups by identifying discursive patterns related to vaccination within the opinions they expressed on the Eurobarometer survey.

The K-Means Cluster Analysis is used to measure the Euclidean distance between homogenous and heterogeneous cases in order to identify structures within the data (Madhulatha, 2012). The analyst establishes the number of clusters and can choose to iterate and classify the cases, or to only classify them. I set the number of clusters to 4 after testing various versions of this analysis with different numbers of clusters and considering the statistical stability and theoretical relevance of the results. I opted for iterating and classifying the cases and I set the maximum iterations to 10. As a method for dealing with the missing values, I used the single imputation - Expectation Maximization (EM) technique. All the 
variables were standardized prior to running the K-Means Cluster Analysis using the z-score standardization method, which was identified as a superior method for standardization before clustering in the light of the accuracy and efficiency of results (Mohamad \& Usman, 2013). The data were weighted using population size weighting in order to adequately represent the population.

\section{Results}

Among the reasons for not getting vaccinated in the last 5 years, 39\% of respondents declare that they do not see the need. $27 \%$ say they are still covered by earlier vaccines, thus, advancing a reason that does not oppose vaccination. Being covered by earlier vaccines accounts for their previous participation in this medical practice. Other people faced structural constraints that impeded them to be vaccinated in the last 5 years. $22 \%$ have not been offered any vaccine by their health care providers, 6\% say vaccines are expensive and 3\% say vaccination is complicated and requires a lot of effort. Therefore, not getting vaccinated is not due to an anti-vaccination attitude in their case. $10 \%$ of respondents tend to associate vaccination with childhood. As a reason for not getting vaccinated, these people say that vaccines are only necessary for children.

Almost half of the participants say that vaccination can often produce serious sideeffects. Almost $40 \%$ rate the affirmation "vaccines can cause the disease against which they protect" as true, and over $32 \%$ consider to be true that vaccines overload and weaken the immune system. Moreover, $10 \%$ of respondents consider false that vaccines are rigorously tested before being authorized for use. The collective benefits of vaccination are contested by some of the respondents. $13 \%$ do not agree with routine vaccination as an important practice for everybody. $9 \%$ deny the importance of vaccines not only for oneself, but also for others. Other $9 \%$ do not agree that vaccination can protect those who cannot be vaccinated. For more information on descriptive statistics, see Table 1.

Table 1. Descriptive statistics for variables used in the analysis

\begin{tabular}{lccc}
\hline Variable & $\%$ & Mean & SD \\
\hline $\begin{array}{l}\text { Why have you not have any vaccination in the last five years? (only } \\
\text { Mentioned answers) }\end{array}$ & & & \\
You are still covered by vaccines you received earlier & 38.6 & 0.39 & 0.48 \\
You do not see the need to be vaccinated & 10.2 & 0.10 & 0.30 \\
Vaccines are only necessary for children & & & 0.44 \\
$\begin{array}{l}\text { You have not been offered any vaccine by your general practitioner, a } \\
\text { doctor, or a paediatrician }\end{array}$ & 22.1 & 0.22 & 0.41 \\
It is expensive & 6.1 & 0.06 & 0.23 \\
$\begin{array}{l}\text { It is complicated and requires a lot of effort } \\
\text { (N) }\end{array}$ & 3.1 & 0.03 & 0.17 \\
\hline
\end{tabular}




\begin{tabular}{|c|c|c|c|}
\hline Variable & $\%$ & Mean & SD \\
\hline \multicolumn{4}{|l|}{$\begin{array}{l}\text { For each of the following statements, could you please tell me whether } \\
\text { you think it is true or false? }\end{array}$} \\
\hline $\begin{array}{l}\text { Vaccines overload and weaken the immune system } \\
\text { (True answers) }\end{array}$ & 32.2 & 0.45 & 0.45 \\
\hline $\begin{array}{l}\text { Vaccines can cause the disease against which they protect } \\
\text { (True answers) }\end{array}$ & 38.8 & 0.49 & 0.46 \\
\hline $\begin{array}{l}\text { Vaccines can often produce serious side-effects } \\
\text { (True answers) }\end{array}$ & 49.5 & 0.60 & 0.45 \\
\hline $\begin{array}{l}\text { Vaccines are rigorously tested before being authorized for use (False } \\
\text { answers) }\end{array}$ & 9.9 & 0.14 & 0.33 \\
\hline$(\mathrm{N})$ & (15704) & & \\
\hline
\end{tabular}

To what extant do you agree or disagree with the following statements? (Only Disagree answers)

\begin{tabular}{lccc}
\hline It is important for everybody to have routine vaccinations & 13.4 & 0.13 & 0.34 \\
Vaccines are important to protect not only yourself but also others & 9.0 & 0.09 & 0.28 \\
& & & 0.90 \\
Vaccination of other people is important to protect those that cannot be \\
vaccinated (e.g. newborn children, immunodepressed or very sick \\
people)
\end{tabular}

Source: Eurobarometer 91.2 Europeans in 2019, The General Data Protection Regulation, Awareness of the Charter of Fundamental Rights of the European Union, and Europeans' attitudes towards vaccination, $\mathrm{N}=15704$; author' analysis

The scores corresponding to the four clusters that I identified using K-Means Cluster Analysis are presented in Table 2. According to these results, "Unexercised pro-vaccination" pertains to people who say they are still protected by earlier vaccines, which is a unique characteristic across the four clusters. Nonetheless, they have not been offered any vaccines by their doctor during the last five years. "Unexercised pro-vaccination" rejects the existence of side effects and acknowledges the collective benefits of vaccination. However, having not received any vaccine in the last five years (even though the influenza vaccine is recommended to be administrated annually - Centers for Disease Control and Prevention, 2019) indicates potential forms of deficits. 
Table 2. Final Cluster Centers EU 28

\begin{tabular}{|c|c|c|c|c|c|}
\hline Euro 28 & & $\begin{array}{l}\text { Unexercised pro- } \\
\text { vaccination }\end{array}$ & $\begin{array}{c}\text { Effort } \\
\text { hesitation }\end{array}$ & $\begin{array}{c}\text { Price } \\
\text { hesitation }\end{array}$ & $\begin{array}{c}\text { Consistent } \\
\text { anti- } \\
\text { vaccination }\end{array}$ \\
\hline No. of cases & & 12838 & 389 & 86 & 2323 \\
\hline \% within EU28 & & 82.1 & 2.5 & 0.5 & 14.9 \\
\hline $\begin{array}{l}\text { Reason for no vaccination in } \\
\text { the last } 5 \text { years: still covered } \\
\text { by earlier vaccine }\end{array}$ & $\begin{array}{c}\text { - Not } \\
\text { mentioned } \\
+ \\
\text { Mentioned } \\
\end{array}$ & 0.09 & -0.23 & -0.33 & -0.35 \\
\hline $\begin{array}{l}\text { Reason for no vaccination in } \\
\text { the last } 5 \text { years: do not see the } \\
\text { need }\end{array}$ & $\begin{array}{c}\text { - Not } \\
\text { mentioned } \\
+ \\
\text { Mentioned }\end{array}$ & -0.04 & -0.35 & -0.34 & 0.20 \\
\hline $\begin{array}{l}\text { Reason for no vaccination in } \\
\text { the last } 5 \text { years: vaccines are } \\
\text { only necessary for children }\end{array}$ & $\begin{array}{c}\text { - Not } \\
\text { mentioned } \\
+ \\
\text { Mentioned } \\
\end{array}$ & 0.00 & 0.24 & 0.11 & 0.04 \\
\hline $\begin{array}{l}\text { Reason for no vaccination in } \\
\text { the last } 5 \text { years: not been } \\
\text { offered by doctor }\end{array}$ & $\begin{array}{c}\text { - Not } \\
\text { mentioned } \\
+ \\
\text { Mentioned } \\
\end{array}$ & 0.05 & -0.03 & -0.08 & -0.21 \\
\hline $\begin{array}{l}\text { Reason for no vaccination in } \\
\text { the last } 5 \text { years: expensive }\end{array}$ & $\begin{array}{c}\text { - Not } \\
\text { mentioned } \\
+ \\
\text { Mentioned } \\
\end{array}$ & -0.02 & -0.25 & 3.93 & 0.02 \\
\hline $\begin{array}{l}\text { Reason for no vaccination in } \\
\text { the last } 5 \text { years: complicated / } \\
\text { a lot of effort }\end{array}$ & $\begin{array}{c}\text { - Not } \\
\text { mentioned } \\
+ \\
\text { Mentioned }\end{array}$ & -0.17 & 5.61 & 5.61 & -0.17 \\
\hline $\begin{array}{l}\text { Vaccines overload and } \\
\text { weaken the immune system }\end{array}$ & $\begin{array}{l}\text { - False } \\
\text { + True }\end{array}$ & -0.11 & 0.00 & 0.20 & 0.53 \\
\hline $\begin{array}{l}\text { Vaccines can cause the disease } \\
\text { against which they protect }\end{array}$ & $\begin{array}{l}\text { - False } \\
+ \text { True }\end{array}$ & -0.08 & 0.03 & 0.16 & 0.37 \\
\hline $\begin{array}{l}\text { Vaccines can often cause } \\
\text { serious side-effects }\end{array}$ & $\begin{array}{l}\text { - False } \\
+ \text { True }\end{array}$ & -0.08 & -0.06 & 0.08 & 0.34 \\
\hline $\begin{array}{l}\text { Vaccines are rigorously tested } \\
\text { before being authorized for } \\
\text { use }\end{array}$ & $\begin{array}{l}\text { - True } \\
+ \text { False } \\
\end{array}$ & -0.17 & 0.41 & 0.54 & 0.89 \\
\hline $\begin{array}{l}\text { It is important for everybody to } \\
\text { have routine vaccinations }\end{array}$ & $\begin{array}{l}\text { - Agree } \\
+ \text { Disagree }\end{array}$ & -0.27 & 0.01 & 0.19 & 1.51 \\
\hline $\begin{array}{l}\text { Vaccines are important to } \\
\text { protect not only yourself but } \\
\text { also others }\end{array}$ & $\begin{array}{l}\text { - Agree } \\
+ \text { Disagree }\end{array}$ & -0.35 & 0.16 & 0.43 & 1.92 \\
\hline $\begin{array}{l}\text { Vaccination of other people is } \\
\text { important to protect those that } \\
\text { cannot be vaccinated (e.g. } \\
\text { newborn children, } \\
\text { immunodepressed or very sick } \\
\text { people) }\end{array}$ & $\begin{array}{l}\text { - Agree } \\
+ \text { Disagree }\end{array}$ & -0.31 & 0.17 & 0.44 & 1.67 \\
\hline
\end{tabular}

standardized variables; weighted data; author's analysis 
In the case of "Effort hesitation", the main reason for the lack of vaccination in the last five years is related to vaccination being complicated and requiring a lot of effort. This cluster also has a high score for distrust of the rigor of vaccines' testing. Moreover, in the case of "Effort hesitation", the importance of vaccination is associated with childhood.

"Price hesitation" occurs because vaccines are considered expensive. "Price hesitation" is also coupled with the perception of vaccination as being complicated and requiring a lot of effort. Lower scores indicate that the "Price hesitation" attitude dismisses the rigorous testing of vaccines and the collective benefits of vaccination. The score for vaccines' side effects is also higher than the mean, which means people manifesting this attitude show an above the average concern for side effects.

"Consistent anti-vaccination" is an attitude manifested by people who do not vaccinate because of vaccines side effects. There is a particular concern of negative effects that vaccines can have on the immune system. This attitude also comprises disagreement with the collective benefits of vaccination and rejection of the need for being vaccinated.

With regard to age distribution, "Price hesitation" is shared more frequently by older people, pertaining to the young-old category, in particular. Compared with the other clusters, there is an increased occurrence of younger age categories manifesting "Effort hesitation". "Unexercised pro-vaccination" and "Consistent anti-vaccination" are more frequent among people aged 35-44 and 45-54. "Unexercised pro-vaccination" and "Effort hesitation" are shared by people having a higher level of education and white-collar occupations compared with the other two clusters. Their socio-economic status being higher, these people face fewer financial difficulties with regard to covering the costs of vaccines. This is particularly relevant for people manifesting "Effort hesitation", who experience other structural constraints instead. Over 55\% of those who did not vaccinate because of "Unexercised pro-vaccination" are women, whereas more than half of those who did not vaccinate because of "Price hesitation", "Effort hesitation" and "Consistent anti-vaccination" are men. Therefore, men are more likely to hesitate towards vaccination. Additional information on socio-demographic variables can be found in Table 3 .

Table 3. Column percentages of socio-demographic variables (\%)

\begin{tabular}{llcccc}
\hline Euro 28 & $\begin{array}{c}\text { Unexercised } \\
\text { pro- } \\
\text { vaccination }\end{array}$ & $\begin{array}{c}\text { Effort } \\
\text { hesitation }\end{array}$ & $\begin{array}{c}\text { Price } \\
\text { hesitation }\end{array}$ & $\begin{array}{c}\text { Consistent } \\
\text { anti- } \\
\text { vaccination }\end{array}$ \\
\hline \multirow{5}{*}{ Age (years) } & $15-24$ & 10.5 & 12.9 & 7.1 & 9.2 \\
& $25-34$ & 15.4 & 16.7 & 16.5 & 15.9 \\
& $35-44$ & 18.0 & 16.7 & 16.5 & 17.7 \\
& $45-54$ & 18.3 & 15.9 & 9.4 & 18.3 \\
& $55-64$ & 16.4 & 13.4 & 22.4 & 16.0 \\
& 65-74 & 14.6 & 15.7 & 22.4 & 17.0 \\
& 75+ & 6.8 & 8.7 & 5.9 & 5.9 \\
\hline \multirow{5}{*}{ Occupation } & Self-employed & 7.4 & 7.5 & 8.2 & 8.0 \\
& Managers & 10.8 & 11.1 & 2.4 & 7.3 \\
& Other white collars & 13.9 & 16.5 & 5.9 & 14.0 \\
& Manual workers & 24.0 & 23.4 & 23.5 & 27.5 \\
& House persons & 4.7 & 4.1 & 4.7 & 4.8 \\
& Unemployed & 6.5 & 6.7 & 12.9 & 6.5 \\
& Retired & 25.9 & 23.4 & 35.3 & 26.0 \\
& Students & 6.7 & 7.5 & 7.1 & 5.9 \\
\hline \multirow{2}{*}{ Education } & Up to 15 years & 12.0 & 11.3 & 10.5 & 14.5 \\
& 16-19 years & 47.6 & 49.1 & 59.3 & 50.1 \\
& 20+ years & 32.9 & 31.2 & 22.1 & 28.6
\end{tabular}




\begin{tabular}{llcccc}
\hline Euro 28 & $\begin{array}{c}\text { Unexercised } \\
\text { pro- } \\
\text { vaccination }\end{array}$ & $\begin{array}{c}\text { Effort } \\
\text { hesitation }\end{array}$ & $\begin{array}{c}\text { Price } \\
\text { hesitation }\end{array}$ & $\begin{array}{c}\text { Consistent } \\
\text { anti- } \\
\text { vaccination }\end{array}$ \\
& Still studying & 6.8 & 7.6 & 7.0 & 6.0 \\
No full-time & 0.6 & 0.8 & 1.2 & 0.9 \\
\hline \multirow{2}{*}{ Gender } & Men & 47.9 & 54.5 & 55.8 & 51.1 \\
& Women & 52.1 & 45.5 & 44.2 & 48.9 \\
\hline
\end{tabular}

Source: Eurobarometer 91.2 Europeans in 2019, The General Data Protection Regulation, Awareness of the Charter of Fundamental Rights of the European Union, and Europeans' attitudes towards vaccination, $\mathrm{N}=$ 15704

Compared with the other EU countries, the "Price hesitation" attitude is more frequent in Austria, Lithuania and Romania, although the percentages are quite low in these countries, too: $2.3 \%, 1.6 \%$ and 1.5 respectively. "Unexercised pro-vaccination" is prevalent in The Netherlands, Finland, Spain, UK, over $90 \%$ of the study population sharing it. "Effort hesitation" is a less frequent attitude compared with "Unexercised pro-vaccination" and "Consistent anti-vaccination". The highest rates indicating "Effort hesitation" can be found in Belgium, Romania and Slovakia - below 10\%. "Consistent anti-vaccination" is a recurrent attitude in Austria, accounting for 35\% of the cases. By contrast, in Portugal, Netherlands and UK the rates for "Consistent anti-vaccination" are below 7\%. Considering the cluster distribution at country level (see Table 4), we can say that "Price hesitation" and "Effort hesitation" represent minority attitudes in all EU countries.

Table 4. Cluster sizes by country (\%)

\begin{tabular}{|c|c|c|c|c|c|}
\hline Euro 28 & $\begin{array}{c}\% \text { recently } \\
\text { unvaccinated } \\
\text { of total } \\
\text { population }\end{array}$ & $\begin{array}{c}\text { Of which: } \\
\text { Unexercised pro- } \\
\text { vaccination }\end{array}$ & $\begin{array}{c}\text { Of which: } \\
\text { Effort } \\
\text { hesitation }\end{array}$ & $\begin{array}{c}\text { Of which: } \\
\text { Price } \\
\text { hesitation }\end{array}$ & $\begin{array}{c}\text { Of which: } \\
\text { Consistent anti- } \\
\text { vaccination }\end{array}$ \\
\hline EU 28 Total & 35 & 82.1 & 2.5 & 0.5 & 14.9 \\
\hline Austria & 35.2 & 58.4 & 4.3 & 2.3 & 35.0 \\
\hline Belgium & 27.9 & 78.2 & 7.4 & 0.4 & 14.0 \\
\hline Bulgaria & 46.5 & 82.8 & 2.2 & 0.5 & 14.5 \\
\hline Croatia & 44.8 & 75.6 & 2.8 & 0.7 & 20.9 \\
\hline $\begin{array}{c}\text { Cyprus } \\
\text { (Republic) }\end{array}$ & 41.8 & 89.7 & 0.6 & 0.0 & 9.7 \\
\hline $\begin{array}{c}\text { Czech } \\
\text { Republic }\end{array}$ & 35.4 & 86.6 & 0.7 & 0.7 & 12.1 \\
\hline Denmark & 24.7 & 88.9 & 1.0 & 1.0 & 9.1 \\
\hline Estonia & 41.6 & 84.2 & 2.0 & 0.5 & 13.2 \\
\hline Finland & 18.4 & 91.5 & 1.1 & 0.4 & 7.1 \\
\hline France & 20.6 & 72.6 & 1.5 & 0.0 & 25.9 \\
\hline Germany & 22.8 & 77.8 & 0.9 & 0.0 & 21.3 \\
\hline
\end{tabular}




\begin{tabular}{|c|c|c|c|c|c|}
\hline Euro 28 & $\begin{array}{c}\text { \% recently } \\
\text { unvaccinated } \\
\text { of total } \\
\text { population }\end{array}$ & $\begin{array}{c}\text { Of which: } \\
\text { Unexercised pro- } \\
\text { vaccination }\end{array}$ & $\begin{array}{c}\text { Of which: } \\
\text { Effort } \\
\text { hesitation }\end{array}$ & $\begin{array}{c}\text { Of which: } \\
\text { Price } \\
\text { hesitation }\end{array}$ & $\begin{array}{c}\text { Of which: } \\
\text { Consistent anti- } \\
\text { vaccination }\end{array}$ \\
\hline \multicolumn{6}{|l|}{ (West) } \\
\hline $\begin{array}{l}\text { Germany } \\
\text { (East) }\end{array}$ & 15.1 & 79.1 & 5.4 & 0.0 & 15.5 \\
\hline Greece & 37.7 & 83.8 & 1.2 & 0.3 & 14.6 \\
\hline Hungary & 56.9 & 81.3 & 3.1 & 0.4 & 15.2 \\
\hline Ireland & 30.5 & 84.3 & 1.6 & 0.5 & 13.6 \\
\hline Italy & 50.8 & 74.2 & 3.4 & 0.4 & 21.9 \\
\hline Latvia & 35.1 & 74.2 & 1.4 & 1.4 & 23.0 \\
\hline Lithuania & 50.9 & 83.5 & 2.8 & 1.6 & 12.1 \\
\hline Luxembourg & 17.0 & 80.6 & 3.1 & 0.0 & 16.3 \\
\hline Malta & 33.0 & 91.1 & 1.2 & 0.0 & 7.7 \\
\hline Netherlands & 18.3 & 93.5 & 0.8 & 0.0 & 5.7 \\
\hline Poland & 53.7 & 86.0 & 3.3 & 0.2 & 10.5 \\
\hline Portugal & 22.0 & 94.6 & 0.0 & 0.0 & 5.4 \\
\hline Romania & 59.7 & 69.5 & 6.4 & 1.5 & 22.6 \\
\hline Slovakia & 38.9 & 82.3 & 4.5 & 0.8 & 12.4 \\
\hline Slovenia & 46.9 & 85.8 & 0.6 & 0.0 & 13.7 \\
\hline Spain & 31.8 & 92.1 & 0.0 & 0.0 & 7.9 \\
\hline Sweden & 18.3 & 88.0 & 3.1 & 0.0 & 8.9 \\
\hline $\begin{array}{c}\text { United } \\
\text { Kingdom }\end{array}$ & 27.0 & 90.4 & 2.8 & 0.0 & 6.8 \\
\hline
\end{tabular}

Source: Eurobarometer 91.2 Europeans in 2019, The General Data Protection Regulation, Awareness of the Charter of Fundamental Rights of the European Union, and Europeans' attitudes towards vaccination, $\mathrm{N}=15704$; weighted data; author's analysis

\section{Discussion}

Hesitancy towards vaccination is not a clear-cut position, but involves a wide array of attitudes. The cluster analysis that I conducted revealed vaccine hesitancy as a set of extended attitudes. According to my results, various forms of hesitancy towards vaccination result from socio-economic and socio-technical systems that generate everyday settings for individuals. The conceptual contribution of this classification resides in the identification of extended hesitancy towards vaccination generated by the costs of vaccines and the difficulty to access 
medical services. In addition, the empirical contribution of my analysis is due to the large amount of Eurobarometer data and its representativity at the European level.

"Price hesitation" and "Effort hesitation" are manifested by people who did not receive any vaccine in the last five years because of structural constraints. The "Price hesitation" attitude reflects structural constraints to a larger extent than "Effort hesitation", since "Price hesitation" is related to both the difficulty of getting vaccinated and the costs of vaccines. This suggests that "Price hesitation" is experienced by people who have low levels of income. This is a different facet of vaccine hesitancy compared with the WHO conceptualization, since "Price hesitation" and "Effort hesitation" occur because some people do not have access to vaccines.

People who manifest "Price hesitation" and "Effort hesitation" face risks that result from the social structure and the social organization of the health system. They represent minorities that are often neglected, since low vaccination coverage is not regarded as emerging from access barriers (at least, not in the European Union). The "Price hesitation" attitude involves rejecting the medical perspective on collective benefits of vaccination, which can be coupled with both individual risks and structural constraints experienced by some people. "Effort hesitation" implies mistrust towards the medical procedures of testing vaccines. These discursive elements integrated within "Price hesitation" and "Effort hesitation" locate the vaccine-hesitant rhetoric within the structural constraints that restrict access to vaccination.

The "Unexercised pro-vaccination" attitude is accompanied by resources to access medical practices such as vaccination, which indicates the importance of economic capital with regard to vaccination attitudes. Trust towards vaccines is a defining aspect of people having the "Unexercised pro-vaccination" attitude, who had engaged with the medical practice of vaccination. They are reportedly covered by earlier vaccines, although they did not get any vaccination in the last five years. In addition, they were not offered any vaccine by their doctor. "Unexercised pro-vaccination" opposes the hesitant/anti-vaxx discourse related to side effects of vaccines and accepts the collective benefits of vaccination. Therefore, people who share this attitude internalized the medical discourse on vaccination, which substantiates their trust in the health system. By incorporating trust in medicine as an expert system, "Unexercised provaccination" is an attitude that grants authority to science and expertise. Their lack of vaccination within the last five years can be interpreted either as a deficient public understanding of science, or as experts' deficit in terms of public communication of science giving rise to a dialogic hesitancy.

"Consistent anti-vaccination" is an attitude positioned genuinely against vaccination, transcending hesitancy. The "Consistent anti-vaccination" attitude comprises rejection of the medical discourse on vaccines and prompts to creating an alternative discourse - the antivaccine discourse. This attitude is characterized by a wide range of motives pertaining to the anti-vaxx discourse: side effects, rejection of collective benefits, rejection of the need to be vaccinated, compromised immune system. According to this discourse, the individual transgresses the collective concerns related to health. Individual benefits and the avoidance of individual risks should be the focal point of the medical practice. This discursive approach illustrates "Consistent anti-vaccination" as a reflexive attitude involving the predilection for managing risks individually.

More than half of the people having the "Consistent anti-vaccination" attitude are men. They perform healthism by engaging reflexively in the socio-medical practices related to healthcare, trying to deconstruct the medical discourse and creating an alternative discourse, infused with what is considered to be junk science. Their contestation of expertise, under the circumstances of demonopolisation of science, emphasizes the attempt to reconstruct the sociomedical realities related to health. This reconstruction, performed by reflexive social actors, is accomplished by placing the individual at the forefront of the process. 
"Price hesitation" is rarely encountered, which implies that very few people who do not vaccinate are impeded by financial difficulties. "Unexercised pro-vaccination" is not related to structural constraints as restricting access to vaccination, due to health policies that remove barriers from access to health services in countries where this attitude is pervasive (OECD/EU, 2018). "Effort hesitation" is present to a higher extent in countries with mistrusted health care systems, such as Romania (Burcea, Toma, \& Papuc, 2014) and Slovakia (OECD, 2017). However, Belgium has the highest rate of "Effort hesitation", although Belgian patients report high levels of satisfaction with the health system. Despite that, there are regional differences with regard to the quality of the Belgian health system. Inequalities in terms of access to healthcare (Buffel \& Nicaise, 2018; Devos et al., 2019) might explain the high rate of "Effort hesitation" among Belgian people.

Structural constraints, such as those giving rise to "Price hesitation" and "Effort hesitation", are caused by deficits in healthcare systems and not necessarily by a knowledge deficit among the population. Vaccine-hesitant discourses are a reaction to systemic risks. These discourses constitute a form of knowledge that accounts for medical limitations and/or dysfunctions within the healthcare system. Dwelling on the "Consistent anti-vaccination" attitude, some people construct a risk culture that exacerbates systemic risks and frames positively individual responses to health-related issues.

This clustering that uncovers discursive resources is relevant because it distinguishes between various hesitant attitudes to vaccination, which is congruent with MacDonald (2015) conceptualization of vaccine hesitancy as a set of views placed on a continuum. Moreover, it documents the extended dimension of vaccine hesitancy, emphasizing the structural constraints that people face in terms of vaccination, economic disadvantage being an important aspect in this regard. However, my analysis did not reveal low economic capital as the main access barrier to vaccination, contrasting with previous studies (Bedford et al., 2018; Peretti-Watel et al., 2019). A set of more complex structural factors, such as economic capital, regional discrepancies, health policies and the social organization of the medical system operate across socio-medical realities and restrict access to vaccination for some people, while prompting others to manufacture an anti-vaccination discourse.

This clustering presents various types of vaccine-hesitant attitudes, emphasizing the discursive elements that are characteristic to each cluster. These elements do not rely solely on individual attitudes or the medical information possessed, but also on social stratification mechanisms that influence vaccine hesitancy. Previous classifications stressed the individual factors involved in vaccine hesitancy, such as the parenting style, the level of information and the ability of understanding medicine/science, whereas my classification reveals the extended dimension that renders vaccine hesitancy an extended attitude, being influenced by economic inequality and expert systems.

\section{Conclusion}

To conclude, vaccine-hesitant attitudes are extended attitudes which are shaped by one's position within the social stratification system and on healthcare system's characteristics. The existence of structural constraints in some social strata accounts for some vaccine-hesitant attitudes. "Price hesitation" and "Effort hesitation" give rise to vaccine-hesitant rhetorics that stem from restricted access to medical services. Additional constraints are characteristic to "Price hesitation". People having this attitude do not vaccinate because of inequality manifested as financial difficulties. Therefore, "Price hesitation" and "Effort hesitation" attitudes reflect a set of barriers that restrict access to vaccination and possibly to other medical practices, too. "Price hesitation" and "Effort hesitation" are minority attitudes, which means that structural constraints are important, but they are not the main cause when it comes to why people do not 
vaccinate. "Consistent anti-vaccination" pertains to reflexive social actors who are preoccupied by individual risks that emerge from expert systems. They retract the authority that was once assigned to experts and seek to manage risks individually. "Unexercised pro-vaccination" legitimizes medicine as an authority to manage health-related risks. This attitude relies on trust in expert systems and is fostered by access to healthcare.

My analysis has certain limitations that are inherent in the method used. Clustering provides an overview on discursive resources related to vaccine-hesitant attitudes across the European Union, but neglects national nuances related to the phenomenon. This cluster analysis was performed on respondents' considerations related to vaccines generally. Future studies could analyse vaccination attitudes related to a particular vaccine, which is highly important for the contextual framework of vaccine hesitancy.

The originality of my approach resides in the emphasis put on the extended dimension of vaccine-hesitant attitudes. Structural mechanisms related to economic capital and inequality, health policies and social organization of the healthcare system constitute sources of hesitant attitudes towards vaccination. The empirical contribution of my analysis consists in addressing the diversity of vaccine-hesitant attitudes by identifying a typology of such attitudes and stressing their central characteristics. Contrasting with previous analyses relying on data that were not perfectly representative for the study population, the Eurobarometer data that I use has a high level of representativeness for EU countries and the United Kingdom, which enables generalizing the results of the cluster analysis.

This clustering facilitates community policies within the EU because it provides a transnational typology of discursive resources and points to the systemic dimension that can be addressed by EU policies. Diminishing the importance of the knowledge deficit approach and addressing the systemic deficits would illuminate particular needs in terms of medical information and experts' intervention. It is particularly important to understand that one type of vaccine hesitancy can translate into another over time, as long as structural constraints are not addressed and mistrust towards health care system and science still have a place to grow. The "Unexercised pro-vaccination" can convert into "Effort hesitation", then into "Price hesitation", as more constraints add up. "Price hesitation" is susceptible to become a "Consistent antivaccination" attitude because of lack of institutional interventions and dialogic approaches. The four clusters that I identified justify the need for tailored interventions in order to tackle the difficulties some people face with regard to health care access and the scientifically derived risks that load the anti-vaxx discourse.

\section{REFERENCES}

Beck, U. (1992). Risk society: Towards a new modernity. London: Sage Publications.

Bedford, H., Attwell, K., Danchin, M., Marshall, H., Corben, P., \& Leask, J. (2018). Vaccine Hesitancy, Refusal and Access Barriers: The Need for clarity in terminology. Vaccine, 36(44), 6556-6558.

Brown, S. (2009). The New Deficit Model. Nature, 4, 609-611.

Brunk, C. G. (2006). Public Knowledge, Public Trust: Understanding the "Knowledge Deficit." Community Genetics, 9, 178-183.

Bucchi, M., \& Neresini, F. (2008). Science and Public Participation. In The Handbook of Science and Technology Studies (pp. 1-1065). Cambridge: The MIT Press.

Buffel, V., \& Nicaise, I. (2018). ESPN Thematic Report on Inequalities in access to healthcare Belgium.

Burcea, M., Toma, S.-G., \& Papuc, R.-M. (2014). Patients' Satisfaction with the Health Care System in the Age of Globalization: The Case of Romania. Transylvanian Review of Administrative Sciences, Special Is, 5 20.

Centers for Disease Control and Prevention. (2019). Vaccine Information for Adults. Retrieved February 17, 2020, from https://www.cdc.gov/vaccines/adults/rec-vac/index.html

Clark, A., \& Chalmers, D. J. (1998). The Extended Mind. Analysis, 58, 10-23.

Constantine, N. A., \& Jerman, P. (2007). Acceptance of Human Papillomavirus Vaccination among Californian 
Parents of Daughters: A Representative Statewide Analysis. Journal of Adolescent Health, 40(2), 108115.

Devos, C., Cordon, A., Lefèvre, M., Obyn, C., Renard, F., Bouckaert, N., ... Meeus, P. (2019). Performance of the Belgian Health System - Report. Brussels.

Downs, J. S., Bruine de Bruin, W., \& Fischhoff, B. (2008). Parents' vaccination comprehension and decisions. Vaccine, 26, 1595-1607.

European Commission. (2019). Eurobarometer 91.2.

Gesis Leibnitz Institute for the Social Sciences. (2019). Eurobarometer 91.2 (2019): Europeans in 2019, The General Data Protection Regulation, Awareness of the Charter of Fundamental Rights of the European Union, and Europeans' attitudes towards vaccination.

Giddens, A. (1999). Risk and Responsibility. The Modern Law Review, 62(1), 1-10.

Jasanoff, S. (2012). Science and Public Reason. London and New York: Routledge.

Keane, M. T., Walter, M. V., Patel, B. I., Moorthy, S., Stevens, R. B., Bradley, K. M., ... Vernon, T. M. (2005). Confidence in vaccination: a parent model. Vaccine, 23(19), 2486-2493.

Kruger, J. (2011). Extended cognition and the space of social interaction. Consciouness and Cognition, 20, 643657.

MacArthur, K. R. (2017). Beyond health beliefs: the role of trust in the HPV vaccine decision-making process among American college students. Health Sociology Review, 26(3), 321-338.

MacDonald, N. E. (2015). Vaccine hesitancy: Definition, scope and determinants. Vaccine, 14(33), 1-4.

Madhulatha, T. S. (2012). An Overview on Clustering Methods. IOSR Journal of Engineering, 2(4), 719-725.

Mohamad, I., \& Usman, D. (2013). Standardization and Its Effects on K-Means Clustering Algorithm. Research Journal of Applied Sciences, Engineering and Technology, 6(17), 3299-3303.

Nature Immunology Editorial. (2008). A case of junk science, conflict and hype. Nature Immunology, 9(12), 1317.

Nichols, T. (2017). The Death of Expertise The Campaign Against Established Knowledge and Why It Matters. New York: Oxford University Press.

OECD. (2017). Improving the efficiency and outcomes of the Slovak health-care system. In ECD Economic Surveys: Slovak Republic (pp. 103-146). Paris: OECD Publishing.

OECD/EU. (2018). Health at a Glance: Europe 2018 State of Health in the EU Cycle. Paris. Retrieved from https://ec.europa.eu/health/sites/health/files/state/docs/2018_healthatglance_rep_en.pdf

Orekes, N., \& Conway, E. (2010). Merchants of doubt. New York: Bloomsbury Press.

Peretti-Watel, P., Ward, J. K., Vergelys, C., Bocquier, A., Raude, J., \& Verger, P. (2019). "I Think I Made the Right Decision ... I Hope I'm Not Wrong'. Vaccine hesitancy, commitment and trust among parents of young children. Sociology of Health \& Illness, 20(20), 1-15.

Perez, S., Shapiro, G. K., Brown, C. A., Dube, E., Ogilvie, G., \& Rosberger, Z. (2015). “I didn’t even know boys could get the vaccine': Parents' reasons for human papillomavirus (HPV) vaccination decision making for their sons. Psychooncology, 10, 1316-1323.

Pouliot, C., \& Godbout, J. (2014). Thinking outside the "knowledge deficit" box. Science \& Society, 15(8), 833835.

Prior, L. (2003). Belief, knowledge and expertise: the emergence of the lay expert in medical sociology. Sociology of Health \& Illness, 25(3), 41-57.

Simis, M. J., Madden, H., Cacciatore, M. A., \& Yeo, S. K. (2016). The lure of rationality: Why does the deficit model persist in science communication? Public Understanding of Science, 25(4), 400- 414.

Sutton, J., Harris, C. B., Keil, P. G., \& Barnier, A. J. (2010). The psychology of memory, extended cognition, and socially distributed remembering. Phenomenology and the Cognitive Sciences, 9(4), 521-560.

Vanderslott, S., Dadonaite, B., \& Roser, M. (2019). Vaccination. Retrieved February 17, 2020, from https://ourworldindata.org/vaccination\#public-support-and-skepticism

Wikforss, A. (2014). Extended Belief and Extended Knowledge. Philosophical Issues, 24, 460-481.

World Health Organization. (2014). Report on the Sage Working Group on Vaccine Hesitancy. 